\title{
Experimental investigation of burning velocities of ultra-wet methane-air-steam mixtures
}

\author{
Eric Albin ${ }^{\mathrm{a}}$, Holger Nawroth ${ }^{\mathrm{a}}$, Sebastian Göke $^{\mathrm{a}}$, Yves D’Angelo ${ }^{\mathrm{b}}$, Christian Oliver Paschereit $^{\mathrm{a}}$ \\ ${ }^{a}$ Technische Universität Berlin, Institut für Strömungsmechanik und Technische Akustik, Hermann-Föttinger-Institut. \\ Müller-Breslau-Str. 810623 Berlin, Germany \\ ${ }^{b}$ Institut National des Sciences Appliquées, Complexe de Recherche Interprofessionnel en Aéro-thermo-chimie. \\ INSA/CORIA CNRS UMR 6614, 76801 St Etienne du Rouvray, Rouen, France
}

\begin{abstract}
Global burning velocities of methane-air-steam mixtures are measured on prismatic laminar Bunsen flames and lifted turbulent V-flames for various preheating temperatures, equivalence ratios and steam mixture fractions at atmospheric pressure. Experiments are conducted on a new rectangular slot-burner. Experimental burning velocities are compared to computed flame speeds of one dimensional adiabatic premixed flames using detailed mechanisms (Konnov 0.5 and GRI Mech 3.0). Mean profiles of radicals $\mathrm{OH}^{*}$ are also extracted from these flames and compared to simulation results.
\end{abstract}

Keywords: premixed combustion, steam, burning velocity, chemiluminescence, $\mathrm{OH}^{*}$

\section{Introduction}

In ultra-wet gas turbines, the heat of the exhaust gases is used to generate steam that is then injected into the combustion chamber. This yields an increase in cycle efficiency at low $N O_{x}$ emissions [1]. Such large amount of steam significantly decreases burning velocity $[10,4]$ and may make the stabilization of the flame difficult. Laminar flame speeds and ignition delays are very fundamental combustion properties of interest to validate kinetic mechanisms and assess the operability of burners. However, few fundamental experimental studies on wet combustion are available in the literature [4] and there still exists a need for more and well-documented experiments, involving different fuels and a wider range of operating conditions. In the literature, previous studies on wet combustion are usually motivated by other contexts and do not provide a lot of fundamental experimental data at lean and ultra-wet conditions. In this paper, we are, therefore, interested in studying the effect of steam on the flame speed and the flame stability up to very high steam content and for a wider range of equivalence ratios.

Measurements of laminar burning velocities on expanding spherical laminar flames at wet conditions may be found in the literature [10, 11, 12]. However, Babkin et al. [10] and Galmiche et al. [12] limited their experiments to stoichiometric methane mixtures, while Koroll et al [11] studied hydrogen mixtures. Recently, Mazas et al. [4,5] measured laminar flame speeds of oxygen-enriched methane flames with steam dilution using a Bunsen burner with various outlet diameters. This study, performed in an oxy-combustion context, does not provide a large set of data for $\mathrm{CH}_{4}$-air-steam mixtures. Bunsen burners have also been used in the past to study $H_{2}$-air-steam burning velocities by Koroll et Mulpuru [6]. Kobayashi et al. [7] made use of a larger Bunsen burner to study the turbulent flame speed at wet conditions and high pressures with $\phi=0.9$. In [29], Seiser et Seshradi evidenced that steam facilitates the extinction of stoichiometric premixed flames using a counterflow burner. Finally, Selle et al. $[15,16]$ measured the laminar burning velocity of methane-air mixtures using a rectangular slot burner with a $10 \times 100 \mathrm{~mm}^{2}$ outlet section at a

Email addresses: eric.albin@campus.tu-berlin.de (Eric Albin), h.nawroth@tu-berlin.de (Holger Nawroth), sebastian.goeke@tu-berlin.de (Sebastian Göke) 
moderate inlet temperature and a low steam content. The influence of steam on the ignition delay has also been assessed experimentally by Wang et al. [23] for $H_{2}$-air steam mixtures $(\phi=0.42)$ and by Gurentsov et al. [24] for stoichiometric methane-air mixtures using shock tube experiments. If kinetic mechanisms may reproduce the tendency of steam to increase the ignition delay for hydrogen mixtures [30], it is interesting to note that steam tends to decrease the ignition delay for stoichiometric methane mixtures in experiments, which is not predicted by reaction mechanisms [24].

For the present study, a rectangular slot-burner with an adjustable outlet section is built to study laminar to slightly turbulent flames at wet conditions and for a wide range of operating conditions $(\phi \in[0.6 ; 1.3]$ up to $\left.T_{u}=480 K\right)$. This burner allows for stabilizing various types of flames like prismatic Bunsen flames or rod-stabilized V-flames. Compared to a standard Bunsen flame, the absence of the flame curvature due to the axisymmetric shape of the flame may be advantageous in order to limit preferential diffusion effects to the tip of the periodical Bunsen flame [17] or near the rod region in case of a lifted V-flame, when studying burning velocities at laminar and turbulent conditions. In the current study, laminar Bunsen flames are stabilized using a slot-width of $10 \mathrm{~mm}$ while turbulent lifted flames are stabilized on a rod using a $35 \mathrm{~mm}$ slot-width. The turbulence level is assessed by hot-wire anemometry. Flame images are recorded using a high speed camera equipped with an $\mathrm{OH}^{*}$ filter. Laminar burning velocities are extracted from Bunsen flames using an area-based method, while turbulent burning velocities are determined from V-flames with an angle-based method. Simulations with detailed chemistry of 1D adiabatic flames are computed using the open-source software Cantera [31] and provide comparisons with experimental data. Profiles of $\mathrm{OH}^{*}$ radicals are also extracted from experiments and a subset of chemistry for $\mathrm{OH}^{*}$ radicals [18] is added to both mechanisms GRI Mech 3.0 [33] and Konnov 0.5 [32]. This allows to provide further comparisons between experiments and 1D simulations.

This paper first describes the new test-rig and typical obtained flames. The post-processing methodology used to extract burning velocity values and $\mathrm{OH}^{*}$ profiles from these flames is then presented in Section 2 . Finally, experimental results of methane-air-steam combustion are analysed and described in Section 3. Burning velocities and profiles of chemiluminescent hydroxyl radicals $\mathrm{OH}^{*}$ are extracted and compared with the flame simulations. Concluding remarks finally end the paper in Section 4.

\section{Experimental Set-Up}

Experiments are conducted on a rectangular slot-burner, equipped with a steam evaporator. A schematic illustrates both the test-rig and its supply lines (Fig. 1). In this set-up, the slot section may be adjusted between $5 \times 100$ to $35 \times 100 \mathrm{~mm}^{2}$ by interchanging the two rectangular wedges. Small outlet sections with the lowest flow rates applied are used to study laminar burning velocities. All parts are made of stainless steel.

A honeycomb and a fine grid, placed in the settling chamber upstream of the nozzle, are used to homogenize and laminarize the flow. The nozzle has been manufactured using electro-erosion technique and polished to ensure a low surface roughness $\left(R_{z} 10\right)$. The nozzle shape, designed to avoid flow separation according to [19], has a constant contraction in the slot-wise direction $(H=100 \mathrm{~mm})$ and a variable width $B_{2}$ in the perpendicular direction. The contraction ratio of the nozzle varies with the slot width according to Table 1.

Table 1: Contraction ratio of the nozzle as a function of the slot width. The contraction ratio $\left(A_{1} / A_{2}\right)$ is defined as the ratio between the entrance section to the exit nozzle section.

\begin{tabular}{c||c|c|c|c|c|c|c}
$B_{2}(\mathrm{~mm})$ & 5 & 10 & 15 & 20 & 25 & 30 & 35 \\
\hline$A_{1} / A_{2}$ & 25 & 13 & 9 & 7 & 5.8 & 5 & 4.43
\end{tabular}

The respective mass flow rates of methane and air are controlled by mass flow meters based on the Coriolis principle and two pneumatically driven control valves. The air is heated with a $1.5 \mathrm{~kW}$ preheater. To reduce heat losses, the preheated air, fuel, and the superheated steam are mixed close to the burner in a joint supply line. A precision evaporator of $3 k W$ (Cellkraft) is chosen to generate pure steam flow of up 


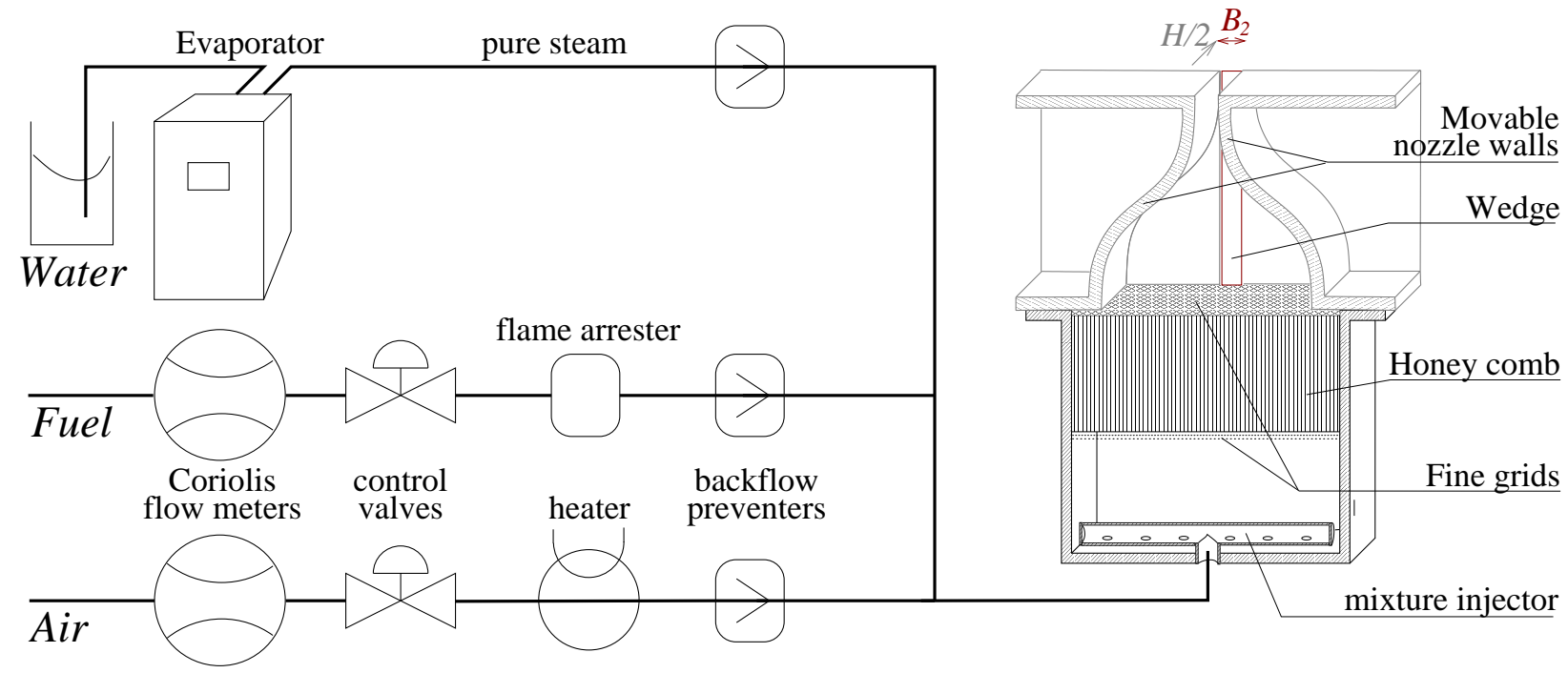

Figure 1: Schematic view of the experimental test-rig and of its supply lines. The slot width may be adjusted between 5 and $35 \mathrm{~mm}$ by substituting the red wedge.

to more than $3 \mathrm{Kg} / \mathrm{h}$ and up to $400^{\circ} \mathrm{C}$. The temperature of the mixture is monitored by a thermocouple at $15 \mathrm{~mm}$ upstream of the nozzle outlet without perturbing the flame. The insulation of the burner with ceramic fibers reduces heat losses to reach preheating temperatures up to $480 K$ at low mass flow rates. All parts of the burner are sufficiently superheated to avoid the red spots and the red chemiluminescence typical of a non-uniform wet water vapor [7].

Typical pictures of prismatic flames are shown in Fig. 2. Throughout this paper, prismatic flames will be obtained using a slot width of $10 \mathrm{~mm}$ (Fig. 2a and $2 \mathrm{~b}$ ) while lifted flames are stabilized on a tungsten rod $(\varnothing 1.5 \mathrm{~mm})$ placed in the center of a slot $35 \mathrm{~mm}$ in width (Fig. 2c).

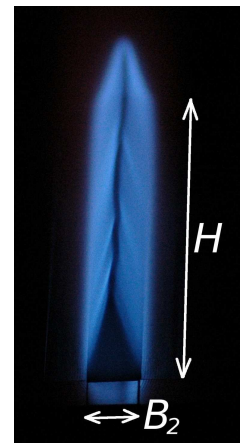

(2a)

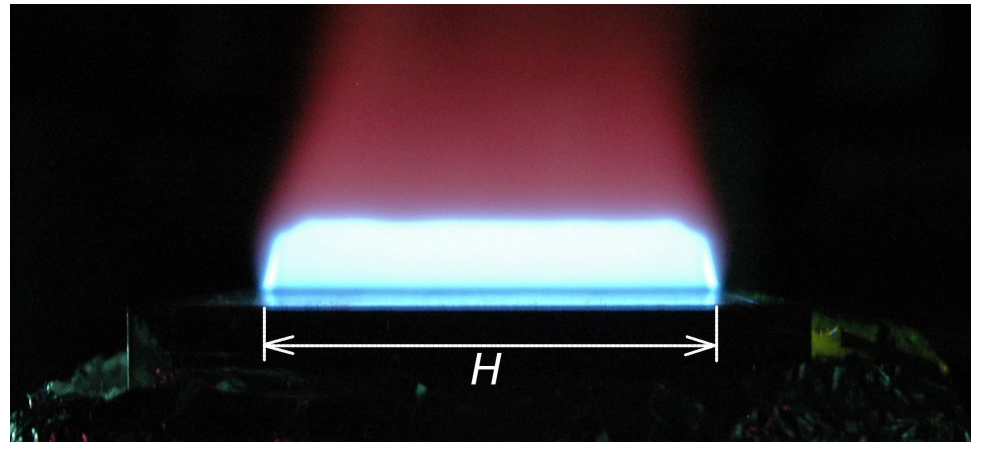

(2b)

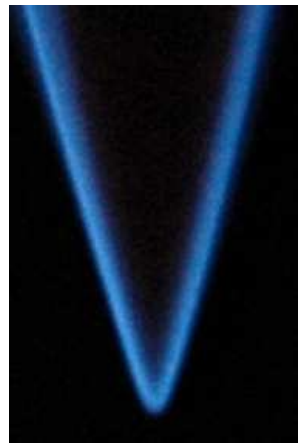

(2c)

Figure 2: Raw image of typical flames stabilized on the rectangular slot-burner. Case (a) and (b) show a $3 D$ and a side view of a prismatic flame at atmospheric conditions $(\phi=0.85, \Omega=0)$ using a slot width of $10 \mathrm{~mm}$. Case (c) is a lifted V-flame, stabilized on a $\varnothing 1.5 \mathrm{~mm}$-rod $\left(T_{u}=480 K, \phi=0.65\right.$ and $\left.\Omega=10 \%\right)$.

The methane-air-steam composition is characterized by the equivalence ratio $\phi$ and the mass dilution 
steam-air ratio $\Omega$ :

$$
\begin{aligned}
\phi & =s \frac{\dot{m}_{C H_{4}}}{\dot{m}_{\text {air }} Y_{O_{2}}^{\text {air }}} \quad \text { with } s=4 \text { and } Y_{O_{2}}^{\text {air }}=0.233 \\
\Omega & =\frac{\dot{m}_{\text {steam }}}{\dot{m}_{\text {air }}}
\end{aligned}
$$

Since the total mass flow of unburnt gases is $\dot{m}_{u}=\dot{m}_{\text {air }}+\dot{m}_{f u e l}+\dot{m}_{\text {steam }}$ and $Y_{i}=\dot{m}_{i} / \dot{m}_{u}$, one can convert directly the parameters $(\Omega, \phi)$ to mass mixture fractions using the following equations :

$$
\begin{aligned}
Y_{\text {air }}^{u} & =1 /\left(1+\Omega+\phi Y_{O_{2}}^{\text {air }} / s\right) \\
Y_{\text {steam }}^{u} & =Y_{\text {air }}^{u} \cdot \Omega \\
Y_{C H_{4}}^{u} & =Y_{\text {air }}^{u} \cdot \phi Y_{O_{2}}^{\text {air }} / s
\end{aligned}
$$

To localize the flame front and extract flame properties like flame angles and lengths, some pictures, from a standard SLR camera, and corresponding images from $\mathrm{OH}^{*}$ chemiluminescence and shadowgraphy are taken and examples are shown in Figure 3. Images from $\mathrm{OH}^{*}$ chemiluminescence are taken using a high speed camera equipped with a band-pass filter around $308 \mathrm{~nm}$ to measure the $\mathrm{OH}^{*}$ chemiluminescence. Shadowgraphy and schlieren techniques have also been used in combination with a high speed camera. As $\mathrm{OH}^{*}$ radicals are a good indicator of the reaction zone and because images from the $\mathrm{OH}^{*}$ chemiluminescence allow a systematical localization of the flame front and contained additional qualitative information about the $\mathrm{OH}$ chemistry, the chemiluminescence images are preferred and only these data are exploited later in this study.
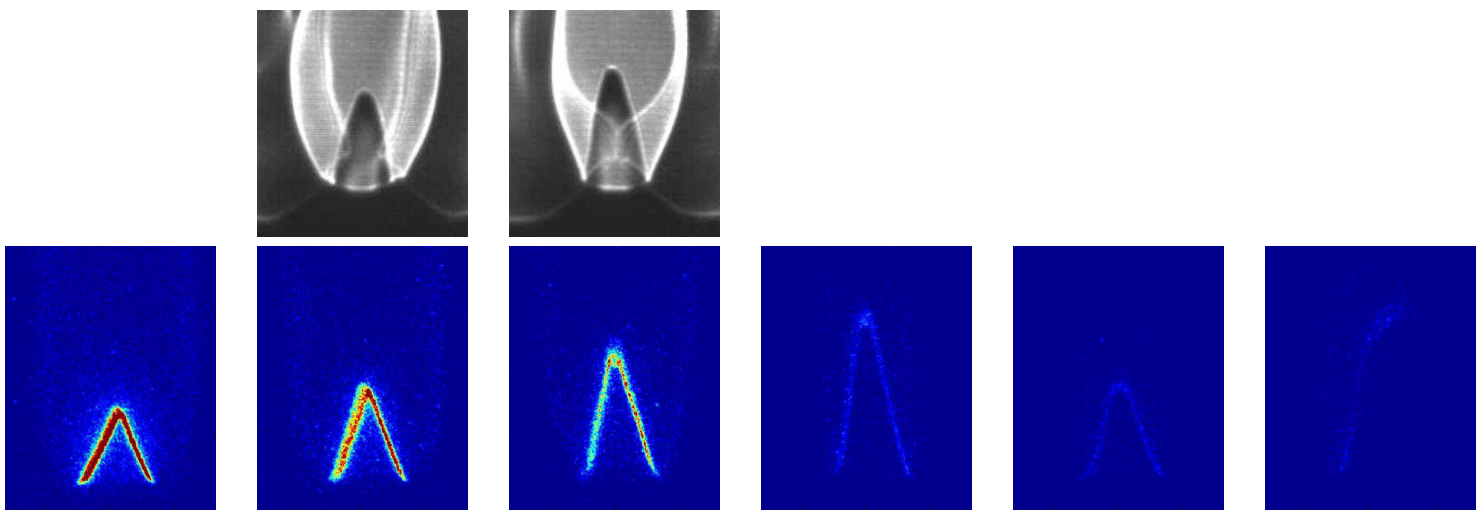

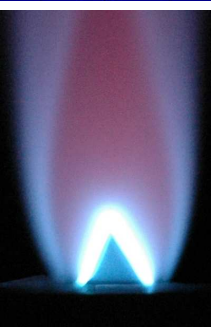

$1.77 \mathrm{~m} / \mathrm{s}$ $\Omega=2.5 \%$

(3a)

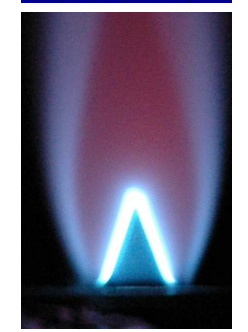

$1.74 \mathrm{~m} / \mathrm{s}$

$\Omega=7.5 \%$

(3b)

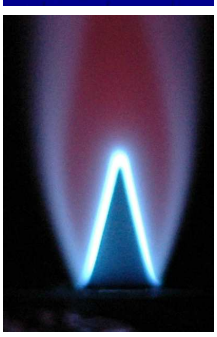

$1.77 \mathrm{~m} / \mathrm{s}$ $\Omega=10 \%$

(3c)

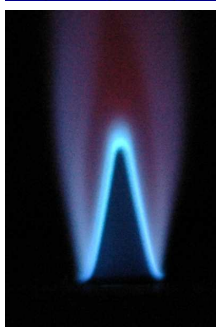

$1.10 \mathrm{~m} / \mathrm{s}$

$\Omega=20 \%$

(3d)

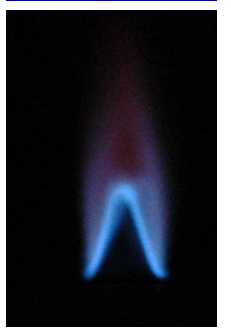

$0.58 \mathrm{~m} / \mathrm{s}$ $\Omega=25 \%$

(3e)

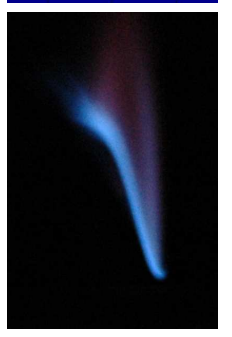

$0.58 \mathrm{~m} / \mathrm{s}$

$\Omega=25 \%$

(3f)

Figure 3: Series of instantaneous pictures of a prismatic flame (side view) when varying the degree of humidity. The bottom pictures are SLR images (shutter speed 1/10s, aperture F-4.5), the middle series are the corresponding OH chemiluminescence images (shutter $0.1 \mathrm{~ms})$ and the top raw represents some shadowgraphs $(1 / 1000 \mathrm{~s})$. The slot width is $10 \mathrm{~mm}$. The equivalence ratio is $\phi=1.2$ and the unburnt temperature is $T_{u}=480 \mathrm{~K}$. The mean outlet velocity $U_{u}$ and the degree of humidity $\Omega$ are indicated at the bottom of each pictures. 
Images (3a) to (3c) highlight the increase of flame area for a constant mass flow rate due to the decrease of the flame velocity when steam is added. For higher steam content, the outlet velocity of unburnt gases is decreased to keep the flame attached. However, the flame can hardly be attached at the edge of the burner with a temperature of $480 \mathrm{~K}$ and $25 \%$ of steam in the air, even for a rich flame $\phi=1.2$. At this condition, the flame oscillates between a prismatic flame, attached on both sides of the slot (3e), and a single side-attached flame (3f).

\section{Post-process strategy}

Mean burning velocities are extracted from lateral $\mathrm{OH}$ chemiluminescence images of Bunsen prismatic flames and lifted V-flames. In case of Bunsen flames, the area of the flame $A_{f}$ is measured and the mean consumption speed $S_{c}$ is deduced from the total mass flow of unburnt gases :

$$
S_{c}=\frac{\dot{m}_{u}}{\rho_{u} A_{f}}
$$

In case of lifted V-flames, the flame angle $\beta$ is defined and measured as the angle between the vertical line and the flame front (Fig. 4c). The mean consumption speed is then deduced from the angle using an angle-based method by :

$$
S_{c}=U_{u} \cdot \sin \beta \quad \text { with } \quad U_{u}=\frac{\dot{m}_{u}}{\rho_{u} A_{2}}
$$

Assuming the unburnt mixture as an ideal gas, its density is calculated from the ideal gas law. The extraction of flame angles, flame lengths and $\mathrm{OH}^{*}$ mean profiles from the $O H$ chemiluminescence images is performed using a robust automated algorithm allowing the recognition of the flame front. For each operating point, a Proper Orthogonal Decomposition is used among 50 pictures to remove the background noise from raw images [20,21]. The reaction zone is then identified by selecting pixels of highest chemiluminescent intensity $I^{*}$ using a fixed threshold value $\left(I_{\text {min }}^{*}+0.4 *\left(I_{\text {max }}^{*}-I_{\text {min }}^{*}\right)\right)$. Spline functions are then determined by a least square method to mathematically describe the flame front and, hence, allow for the estimation of flame angles and lengths.

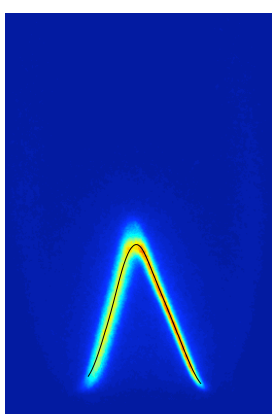

$\Omega=7.5 \%$

$\phi=1.2$

$1.74 \mathrm{~m} / \mathrm{s}$

(4a)

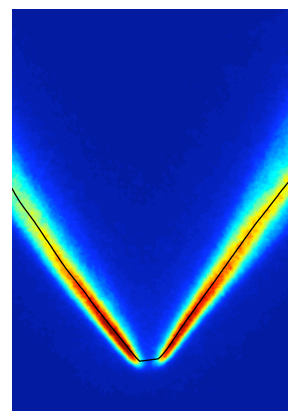

$\Omega=0 \%$

$\phi=0.7$

$1.73 \mathrm{~m} / \mathrm{s}$

(4b)

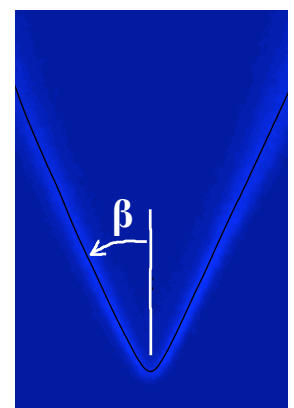

$\Omega=15 \%$

$\phi=0.8$

$1.16 \mathrm{~m} / \mathrm{s}$

(4c)

Figure 4: Examples of typical flames fitted by a spline. One of the 50 smoothed POD pictures using a Proper Orthogonal Decomposition is fitted by a spline (dark line).

Splines are briefly presented using the usual notation [22] and the notation compatible with Matlab since the identification of coefficients is required to compute spline lengths. An elementary cubic spline is defined by a third order polynomial restricted to a segment $\left[\xi_{i-1} ; \xi_{i}\right]$ :

$$
s_{i}(x)=\left\{\begin{array}{lll}
a_{i, 0}+\sum_{j=1}^{3} a_{i, j}\left(x-\xi_{i-1}\right)^{j} & \text { if } & x \in\left[\xi_{i-1} ; \xi_{i}\right] \\
0 & \text { if } \quad x \notin\left[\xi_{i-1} ; \xi_{i}\right]
\end{array}\right.
$$


The spline $s(x)$ that is fitted to high $\mathrm{OH}^{*}$ intensities is a sum of splines on adjacent segments $\left[x_{\text {min }}=\right.$ $\left.\xi_{0}<\xi_{1}<\ldots<\xi_{k}<\xi_{k+1}=x_{\max }\right]$, separated by $k$ knots. Fitting splines on a series of pixels $y_{\text {data }}(x)$ consists in minimizing the expression $\int_{x_{\min }}^{x_{\max }}\left(y_{\text {data }}(x)-s(x)\right)^{2} d x$ while maintaining continuous derivatives at each nodes. When introducing the parameterization $\boldsymbol{r}_{\boldsymbol{i}}(t \equiv x)=x \boldsymbol{x}+s_{i}(x) \boldsymbol{y}$ of the elementary spline, one can show the length of one elementary spline is equal to $\int_{\xi_{i-1}}^{\xi_{i}}\left\|\boldsymbol{r}_{\boldsymbol{i}}^{\prime}(x)\right\| d x=\int_{\xi_{i-1}}^{\xi_{i}} \sqrt{1+\left(s_{i}^{\prime}(x)\right)^{2}} d x$. The length of the flame is then computed by the following numerical estimation:

$$
L_{f}=\sum_{i=1}^{k+1} \int_{\xi_{i-1}}^{\xi_{i}} \sqrt{1+\left(s_{i}^{\prime}(x)\right)^{2}} d x
$$

and the total flame surface is equal to $A_{f}=H \cdot L_{f}$ assuming the prismatic triangular flame is uniform along the slot.

In case of lifted V-flames stabilized on the rod at $x=0$, the mean flame angles $\beta_{1}$ and $\beta_{2}$, defined between the vertical and the left and right flame fronts, are estimated from the derivative of the spline :

$$
\begin{aligned}
& \beta_{1}=\frac{1}{x_{2}-x_{1}} \cdot \int_{x_{1}=-1 \mathrm{~cm}}^{x_{2}=-0.2 \mathrm{~cm}}\left|\arctan \left(\frac{1}{s_{i}^{\prime}(x)}\right)\right| d x \\
& \beta_{2}=\frac{1}{x_{2}-x_{1}} \cdot \int_{x_{1}=0.2 \mathrm{~cm}}^{x_{2}=1 \mathrm{~cm}}\left|\arctan \left(\frac{1}{s_{i}^{\prime}(x)}\right)\right| d x
\end{aligned}
$$

This integral expression is used to smooth the limited fluctuations present on the local angle ; the positions at $\pm 0.2 \mathrm{~cm}$ from the rod are deliberately unconsidered due to the stretch of the flame that affects the local angle at these positions. In practice, we average both flame angles.

The mean $\mathrm{OH}^{*}$ profiles across the flame front is also estimated from the chemiluminescence data to be later qualitatively compared with profiles obtained from one-dimensional simulations. In order to do so, the $\mathrm{OH}^{*}$ intensity is estimated along 30 lines uniformly spaced in $x$-direction and perpendicular to the fitted spline. The normal vector to the spline $\boldsymbol{N}=\boldsymbol{z} \wedge \boldsymbol{T}=\left(-s_{i}^{\prime}(x) \boldsymbol{x}+\boldsymbol{y}\right) / \sqrt{1+\left(s_{i}^{\prime}(x)\right)^{2}}$ points towards unburnt gases, $\boldsymbol{T}(x)=\boldsymbol{r}_{\boldsymbol{i}}^{\prime}(x) /\left\|\boldsymbol{r}_{\boldsymbol{i}}^{\prime}(x)\right\|$ being the tangential vector to the spline. On each line, 100 points are extracted from the image using a bilinear interpolation at $\pm 2 \mathrm{~mm}$ from the spline. The normal distance to the flame front will be denoted $\eta$. A mean profile is then computed from these local profiles, assuming that the $\mathrm{OH}^{*}$ mixture fraction does not depend too much on the local flame curvature and flame stretch.

\section{Experimental results \& discussion}

\subsection{Measurement of the turbulence}

The uniformity of the flow and the turbulence level at the nozzle exit have been measured with the two-component hot-wire anemometry technique (X-Probe, Dantec). The diameter of the hot-wire is $5 \mu m$ and ensures a spatial resolution of $1.2 \mathrm{~mm}$. The root mean square velocity, measured $5 \mathrm{~mm}$ downstream of the slot exit, is given in Table 2 for the various operating conditions presented in the following. Note that the presented values are averaged over various equivalence ratio. The reader may note that the mean outlet velocity decreases with the steam content in order to keep the flame stabilized on the burner. The laminar flame speed is estimated from simulations using GRI Mech 3.0. These hot-wire measurements prove that the flow is sufficiently laminar for Bunsen flame measurements whereas the flow is moderately turbulent in case of the lifted flames. Indeed, a larger slot-width yields higher flow velocities through the honey comb and the fine grid, which generates a higher turbulence level $\left(u_{r m s} / S_{L}>50 \%\right.$ for some cases).

In the low turbulence regime, the turbulence wrinkles the flame and increases its area without modifying the inner structure of a laminar flame. The turbulent flame speed, $S_{T}$, is then increased, compared to the laminar flame speed, by the flame wrinkling factor $A_{T} / A_{L}$ [27] as described by equation (8).

$$
\frac{S_{T}}{S_{L}}=\frac{A_{T}}{A_{L}}
$$


Table 2: Turbulence levels for the different operating conditions. The root mean square velocity is calculated from hot-wire measurements.

\begin{tabular}{|c|c|c|c|c|c|c|c|c|c|}
\hline \multirow[b]{2}{*}{$T_{u}(K)$} & \multirow[b]{2}{*}{$\Omega$} & \multicolumn{4}{|c|}{ Bunsen (10mm slot-width) } & \multicolumn{4}{|c|}{ V-flame (35 $\mathrm{mm}$ slot-width) } \\
\hline & & $U_{u}(m / s)$ & $u_{r m s} / U_{u}$ & $U_{u} / S_{L}$ & $u_{r m s} / S_{L}$ & $U_{u}(m / s)$ & $u_{r m s} / U_{u}$ & $U_{u} / S_{L}$ & $u_{r m s} / S_{L}$ \\
\hline 400 & 0.00 & 1.48 & $0.82 \%$ & 2.6 & $2.1 \%$ & 1.68 & $12.9 \%$ & 4.5 & $54.7 \%$ \\
\hline 400 & 0.05 & 1.17 & $0.64 \%$ & 3.0 & $1.9 \%$ & 1.61 & $11.9 \%$ & 4.6 & $53.9 \%$ \\
\hline 400 & 0.10 & 1.10 & $0.62 \%$ & 4.5 & $3.0 \%$ & 1.15 & $6.4 \%$ & 4.7 & $30.0 \%$ \\
\hline 400 & 0.15 & 0.64 & $0.50 \%$ & 3.5 & $1.7 \%$ & 0.86 & $3.7 \%$ & 4.1 & $15.4 \%$ \\
\hline 400 & 0.20 & 0.50 & $0.57 \%$ & 7.2 & $4.2 \%$ & 0.59 & $2.0 \%$ & 3.7 & $7.4 \%$ \\
\hline 480 & 0.00 & 1.64 & $0.93 \%$ & 2.5 & $2.3 \%$ & 1.80 & $15.5 \%$ & 2.9 & $46.0 \%$ \\
\hline 480 & 0.05 & 1.65 & $0.94 \%$ & 3.0 & $2.8 \%$ & 1.77 & $14.2 \%$ & 3.6 & $50.2 \%$ \\
\hline 480 & 0.10 & 1.64 & $0.93 \%$ & 3.7 & $3.5 \%$ & 1.87 & $15.7 \%$ & 4.3 & $68 \%$ \\
\hline 480 & 0.15 & 1.13 & $0.63 \%$ & 3.9 & $2.5 \%$ & 1.17 & $6.6 \%$ & 3.8 & $24.9 \%$ \\
\hline 480 & 0.20 & 1.09 & $0.60 \%$ & 7.4 & $4.5 \%$ & 1.07 & $6.2 \%$ & 4.1 & $29.7 \%$ \\
\hline
\end{tabular}

\subsection{Stoichiometric consumption speeds}

The mean consumption speed of methane-air mixtures is measured on Bunsen flames and lifted V-flames at atmospheric condition as described previously. Throughout this report, V-flame experimental points are represented by a downward facing triangle $(\boldsymbol{\nabla})$ and Bunsen flames by an upward facing triangle $(\triangle)$ to make an analogy with the shape of these flames. For measurements with steam, the unburnt temperature was $400 K$ and $480 K$ at $\pm 5 K$. Figure 5 compares the measured consumption speed for a stoichiometric methaneair flame at $480 K$ to previous experimental data of Babkin et al. [10] and Mazas et al. [4, 5] obtained at $473 \mathrm{~K}$. As it was presented by these authors, the burning velocity of the wet flame is normalized by the flame speed of the dry mixture to highlight the effect of steam.

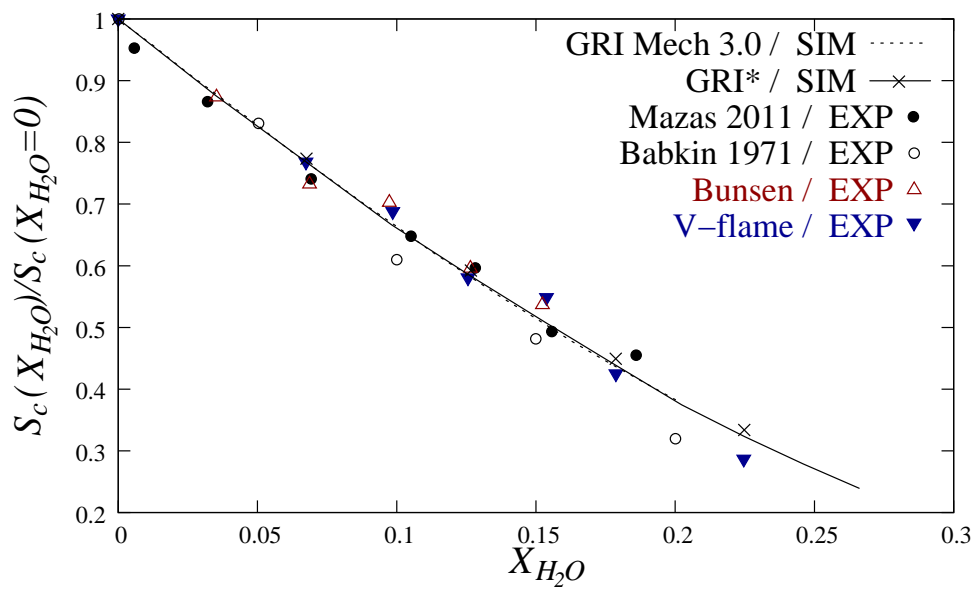

Figure 5: Comparison of measured consumption speed with previous available experiments and computed laminar flame speeds for stoichiometric methane-air flames. The present measurements are performed on Vflames and prismatic Bunsen flames at 480K (colored triangles). Previous experiments of Babkin et al. [10] and Mazas et al. [4, 5] are measured at $473 K$ (black circles). Simulations are computed with the GRI-Mech 3.0 mechanism at $473 \mathrm{~K}$ and the modified $\mathrm{GRI}^{*}$ mechanism at $480 \mathrm{~K}$.

The good agreement between our measurements and previous experiments allows to validate the measurement method. Measurements are also compared to laminar flame speeds determined from 1D simulations of laminar adiabatic unstretched flames with detailed mechanisms. The modified version of the detailed GRI Mech 3.0 mechanism, denoted GRI* throughout the report (resp. Konnov* for Konnov 0.5), includes a subset of chemistry for $\mathrm{OH}^{*}$ radicals [18] in order to provide later further validation with the measured $\mathrm{OH}^{*}$ chemiluminescence. The solver Cantera [31] is used with mixture-averaged diffusion coefficients. Some 
simulations are also computed with the multi-component transport model and these simulation points are represented by crosses (see Fig. 5 to Fig. 8) to ensure that simulations using a mixture-averaged assumption are relevant. Since the concentration of $\mathrm{OH}^{*}$ is very low compared to its ground species, the effect on the whole combustion mechanism is small [2]; it is evident in Fig. 5 that GRI* gives similar results to GRI Mech 3.0 and that computed flame speeds compare well with measurements. At ultra-wet conditions, the stoichiometric methane-air flame speed is observed to be less than one third of the speed of a dry flame. Even if measured consumption speeds are higher in turbulent lifted V-flames than in laminar Bunsen flames, it may be noticed that the wet to dry ratio between the mean consumption speeds compares well for both cases.

In the sequel, measurements of methane-air-steam flames are presented for a wider range of operating conditions. In the sake of clarity, measurements of Bunsen flames are first compared to laminar flames; turbulent $\mathrm{V}$-flames are presented in a separate section and profiles of $\mathrm{OH}^{*}$ chemiluminescence in a final section. To give an indication of the stability of the flame, all the presented results are obtained until the flame detaches from the burner on the lean side and are stopped at $\phi \simeq 1.3$ on the rich side.

\subsection{Measurements on prismatic Bunsen flames}

Figures $6 \mathrm{a}$ and $6 \mathrm{~b}$ plot the measured burning velocity of methane-air-steam mixtures as a function of the equivalence ratio for different steam content up to $\Omega=0.2$ respectively at $400 K$ and $480 K$. As

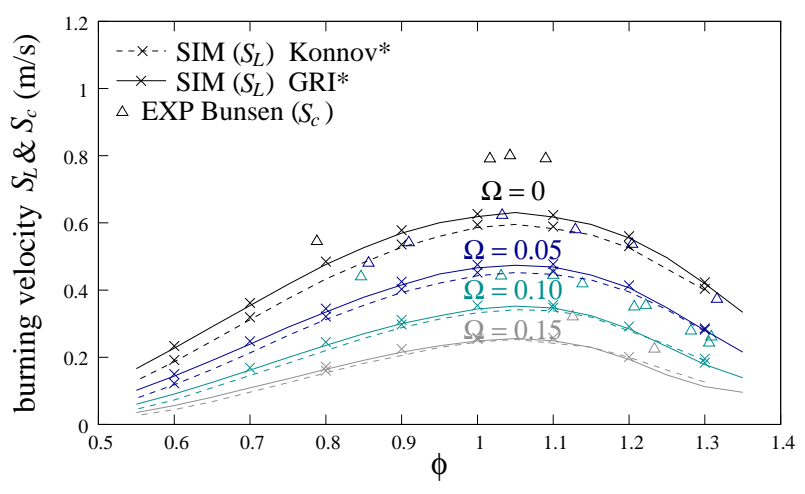

(6a) $T_{u}=400 K$

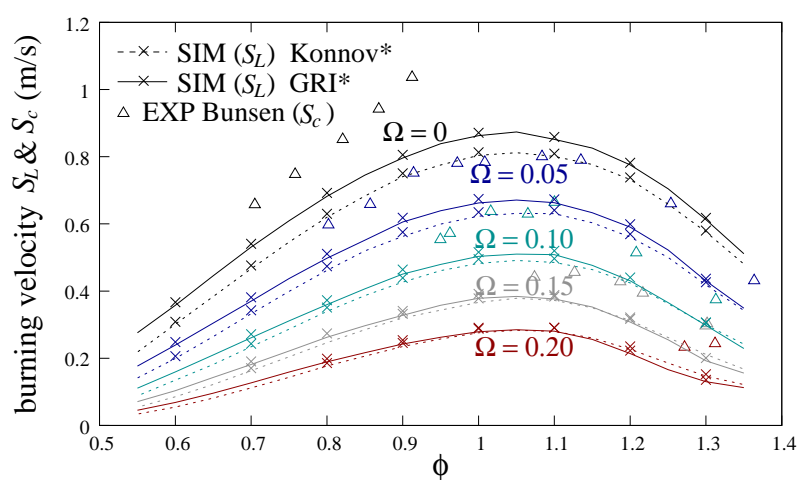

(6b) $T_{u}=480 K$

Figure 6: Comparison of simulated and measured burning velocity of methane-air-steam mixtures. Burning velocities are represented as a function of the equivalence ratio for different steam dilution ratio.

before, burning velocities of Bunsen flames are slightly higher than those of a laminar planar flame. As it is already known in the literature $[10,6,5]$, these figures show that steam addition strongly decreases the flame speed. Bunsen flames were particularly difficult to attach to the burner for lean and wet conditions, which explains the lack of data at such conditions. The stabilization of the flame is slightly better for the highest temperature.

\subsection{Measurements of turbulent burning velocity}

These measurements of quasi-laminar flame speeds are now compared to turbulent burning velocities extracted from rod-stabilized flames at $400 K$ (Fig. 7) and $480 K$ (Fig. 8). Because the turbulence is sufficiently low not to affect the inner structure of the flame, experimental data are also compared to simulations with the GRI* mechanism by assuming a constant flame wrinkling factor. Correlations exist to describe the turbulent/laminar ratio of methane-air flame speed as a function of the turbulence intensity [26]. However, such correlations do not successfully quantify the wrinkling factor. Note that other reasons like measurement uncertainties, Helmholtz resonance, boundary layers, stretch-curvature effects and preheating of the mixture near the walls could explain some deviations and require further investigation in the future. In this work, a low constant wrinkling flame factor of 1.28 is chosen for Bunsen flames to reach a satisfactory agreement between experiments and simulations. Larger factors are required for V-flames because of the increased 
level of turbulence. Note that a factor of 2.57 at $400 K(2.4$ at $480 K)$ is chosen because the ratio $u_{r m s} / S_{L}$ is higher at nearly dry conditions and $400 \mathrm{~K}$ (see Table 2 ).

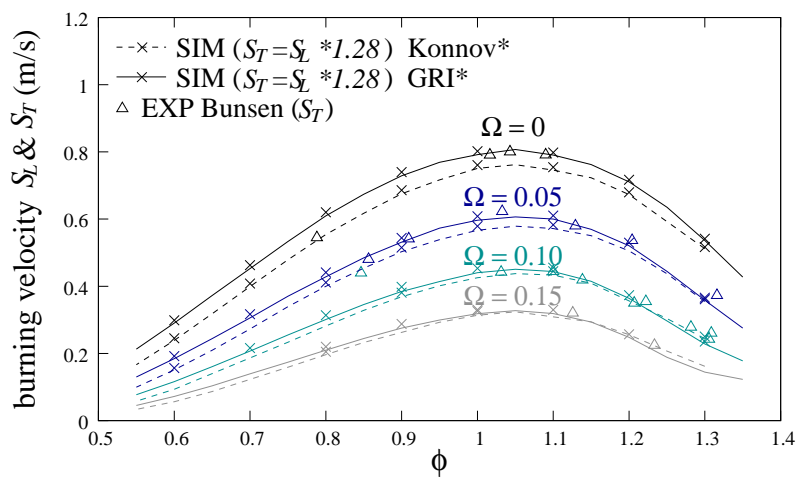

(7a) prismatic flame experiments

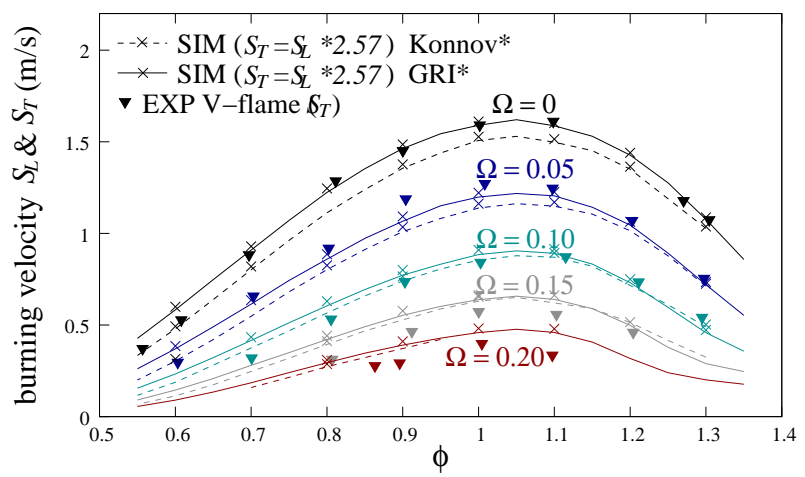

(7b) V-flame experiments

Figure 7: Comparison of simulated and measured turbulent burning velocity of methane-air-steam mixtures at 400K. Burning velocities are represented as a function of the equivalence ratio for different steam dilution ratio.

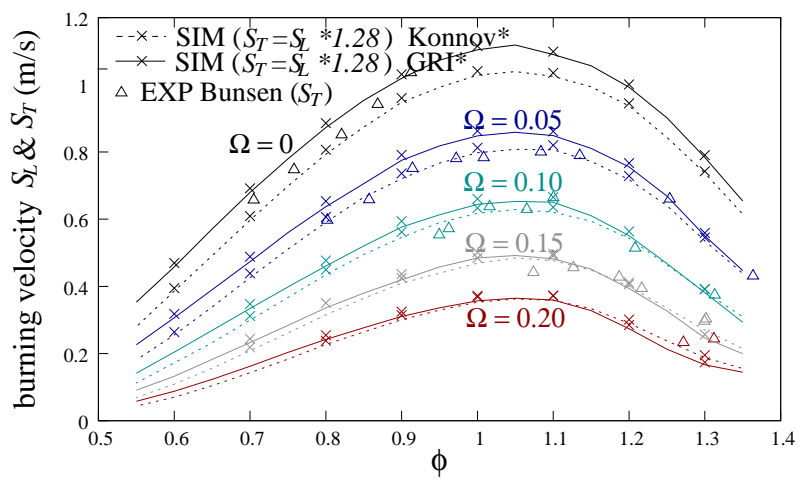

(8a) prismatic flame experiments

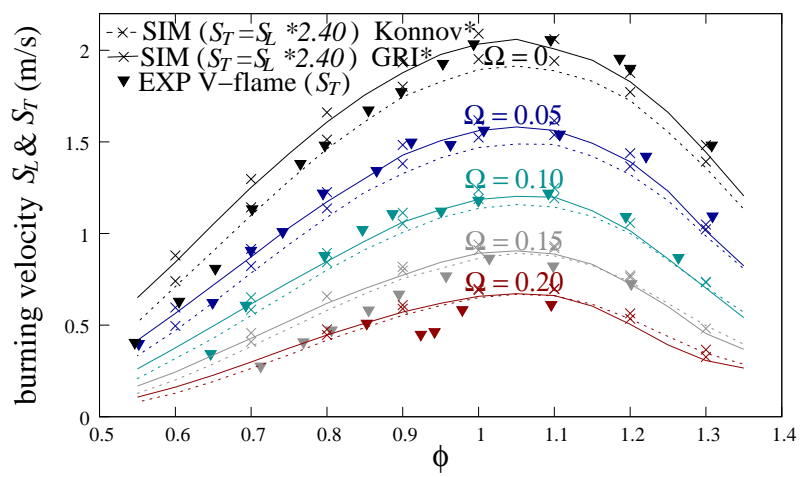

(8b) V-flame experiments

Figure 8: Comparison of simulated and measured turbulent burning velocity of methane-air-steam mixtures at 480K. Burning velocities are represented as a function of the equivalence ratio for different steam dilution ratio.

The agreement between experiments and one-dimensional adiabatic flame simulation again satisfyingly supports the flame-wrinkling assumption. At lean conditions, methane-air-steam V-flames are better stabilized than Bunsen flames. At rich conditions, Bunsen flames are well attached to the burner while lifted flames also get attached to the burner to form a M-shaped flame. For richer conditions, the rod cannot sustain the flame that is only attached at the edge of the slot. These reasons explain why more experimental points are present at the lean side for rod-stabilzed flames while more points are present at the rich side for Bunsen flames (compare Fig. 7a to 7b and Fig. 8a to 7b).

Additional measurements have been performed to plot this turbulent burning velocity as a function of the steam dilution ratio (Fig. 9). The same conclusions as for Figures 7 and 8 can be drawn. The decrease of turbulent burning velocity is well captured by experiments and fits GRI* simulations, assuming wrinkling flame factors to be constant for the two flame configurations at $400 K$ and $480 K$. At lean conditions, a wet flame is much easier to stabilize on a rod than on the edge of the slot, which makes the lifted Vflame configuration complementary to the Bunsen method. The difference of stability may be explained by a difference of implied mechanisms to stabilize the flame. Stabilization mechanisms may be complex and beyond the scope of this paper. Nevertheless, it may be noticed that the attachment configuration is fundamentally different for the lifted and the Bunsen flame. In the Bunsen configuration, the flame is attached on the edge of the slot where a recirculation of air is present (see the extinction of $\mathrm{OH}^{*}$ radicals 


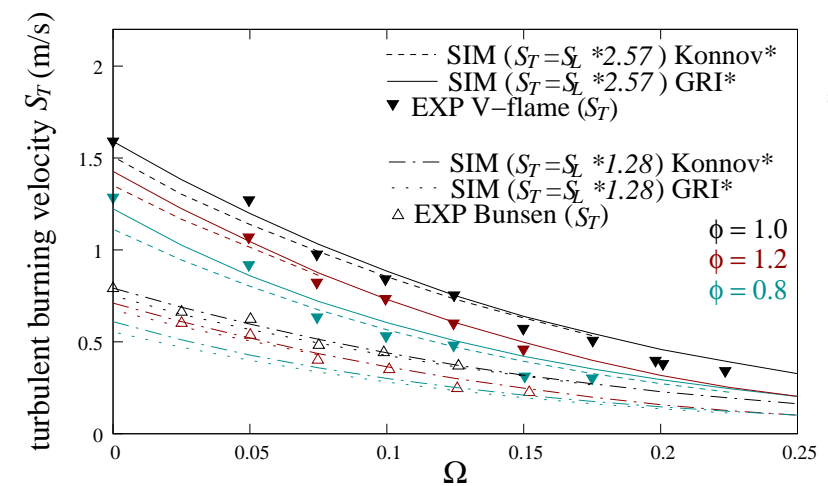

(9a) $T_{u}=400 K$

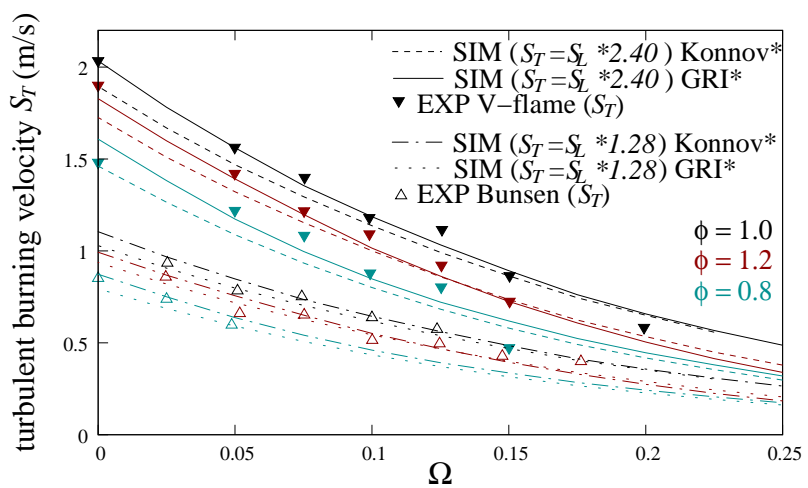

(9b) $T_{u}=480 K$

Figure 9: Comparison of simulated and measured turbulent burning velocity of methane-air-steam mixtures at 480K. Flame speeds are represented as a function of the steam dilution ratio for a lean, a stoichiometric and a rich flame.

at the flame basis of Fig. 3d). It is believed that this recirculation of air plays an important role to further decrease the burning velocity of lean wet mixtures at the flame basis and avoids the stabilization of prismatic flames at those conditions. This phenomenon could be an advantage to stabilize rich conditions. In the case of rod-stabilized flames, unburnt mixtures are present on both sides of the rod and no surrounding air is present to disturb the attachment of the flame at such lean conditions.

\subsection{Profiles of $\mathrm{OH}^{*}$ chemiluminescence}

The luminous signal emitted by the chemiluminescence of $\mathrm{OH}^{*}$ radicals is qualitatively compared in Fig. 10 to the mole fraction $X_{O H^{*}}$ computed from laminar adiabatic flames with the GRI* mechanism. At this low pressure, $X_{O H^{*}}$ is approximately proportional to the $\mathrm{OH}^{*}$ chemiluminescence [2]. The profiles are plotted as a function of the distance $\eta$ to the flame front, previously described at the last paragraph of Section 2, for 3 different steam contents $(\Omega=0, \Omega=0.1$ and $\Omega=0.2$ ) at $480 K$ and for 3 equivalence ratio $(\phi=0.8, \phi=1$ and $\phi=1.3)$; they are also plotted for the lean condition at $400 K$ to see the effect of the temperature.

Figure 10 shows that the mean experimental $\mathrm{OH}^{*}$ profiles do not have the same thickness than those predicted by the simulation of a one-dimensional laminar flame. This difference may be explained by the fact that the wrinkling of the flame leads to a thickening of the mean profiles. The solid angle of the camera, and the non-uniformity of the flame along the slot, notably at the two ends (see Fig. 2), also tends to thicken the experimental profiles. Nevertheless, the maximum of the $\mathrm{OH}^{*}$ peak is in satisfactory agreement between experiments and simulations for a constant calibration of the experimental signal. The largest difference between experiments and the predicted concentration by the GRI* mechanism is at the stœchiometry and at the highest steam content. Experiments with prismatic flames give relatively similar concentrations as the V-flame experiments.

This figure 10 evidences that the steam significantly reduces the chemiluminescence of hydroxyl radicals. Note that concentrations are plotted in a logarithmic scale and these variations are spread over several order of magnitudes. As predicted by GRI* and Konnov* mechanisms, the highest luminous intensity is observed at the stœchiometry and decreases at lean and rich conditions. The mechanism also predict the observed increase of chemiluminescence when the temperature is increased from $400 K$ to $480 K$ at $\phi=0.8$.

The maximum concentration of $\mathrm{OH}^{*}$ is now plotted as a function of the adiabatic flame temperature in Fig. 11 and appears to be very low for low flame temperatures, e.g. for leanest flames. It increases rapidly till the stoichiometry and decreases afterwards again for rich conditions (see loops on Fig. 11). As it was observed experimentally for $\mathrm{OH}^{*}$, reaction mechanisms confirm that steam strongly participates in the reduction of $\mathrm{OH}^{*}$ chemiluminescence (see Fig. $11 \mathrm{~b}$ at $2150 \mathrm{~K}$ ). It is worth noticing that steam significantly decreases $\mathrm{OH}^{*}$, even for a constant flame temperature. This indicates that steam modifies reaction pathways and could explain why $N O_{x}$ emissions are reduced in presence of steam, even at a constant flame temperature [2, 28]. 


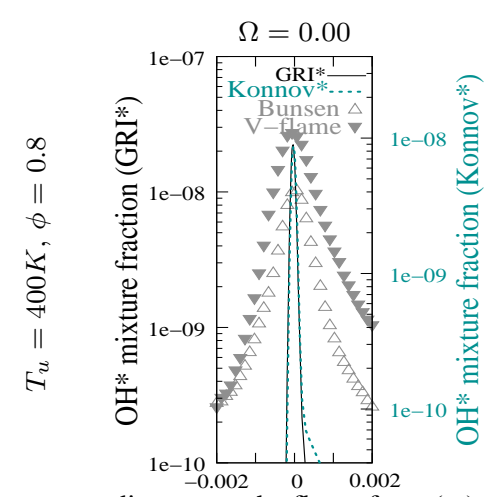

distance to the flame front $(\mathrm{m})$

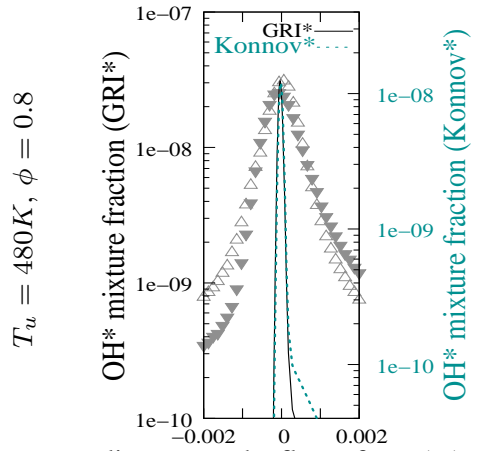

distance to the flame front $(\mathrm{m})$

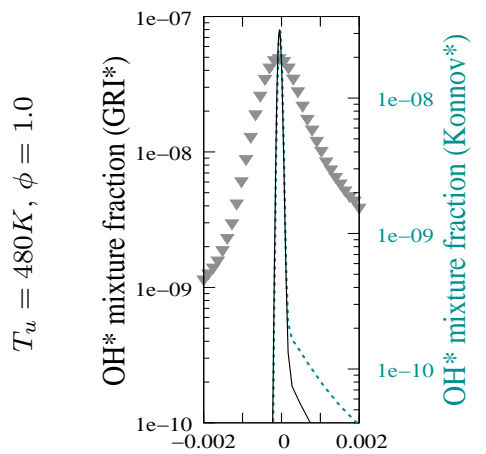

distance to the flame front $(\mathrm{m})$

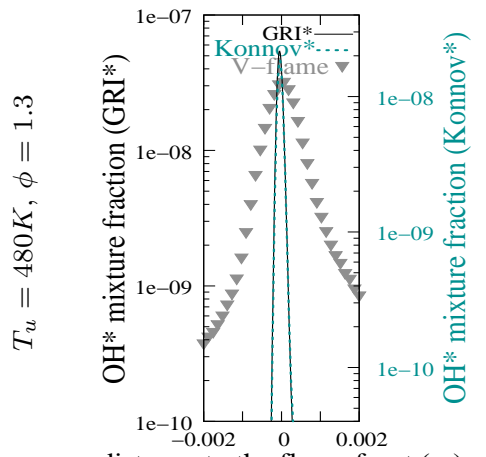

distance to the flame front $(\mathrm{m})$

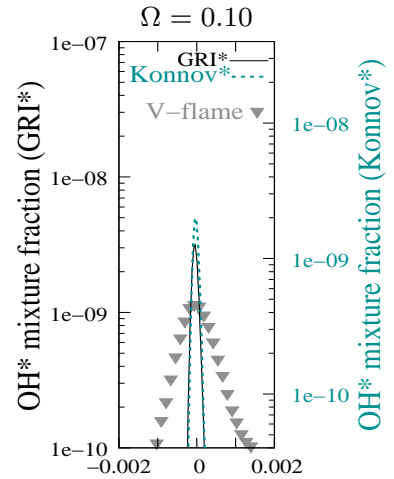

distance to the flame front (m)

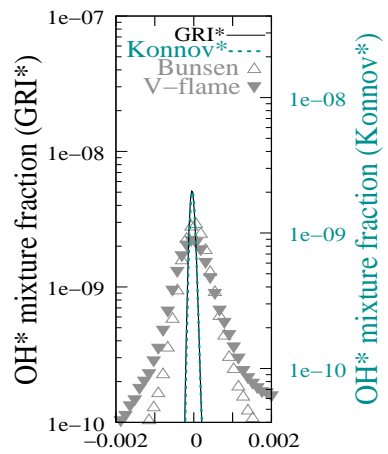

distance to the flame front $(\mathrm{m})$

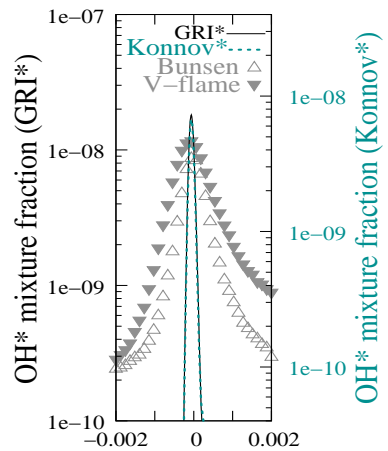

distance to the flame front (m)

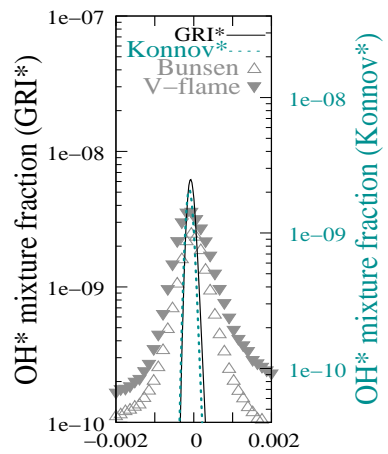

distance to the flame front (m)

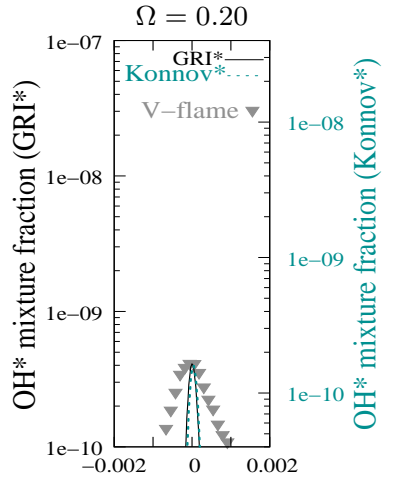

distance to the flame front $(\mathrm{m})$

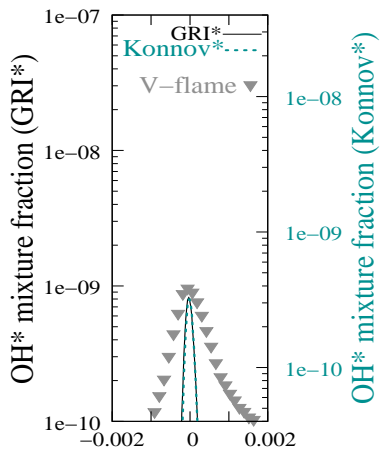

distance to the flame front $(\mathrm{m})$

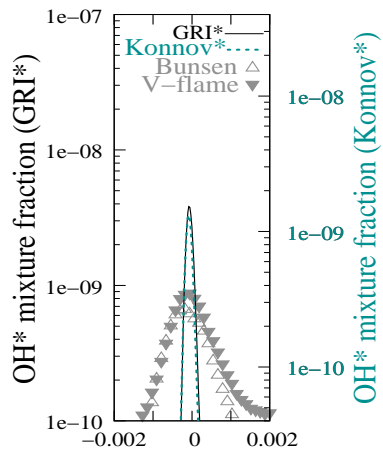

distance to the flame front $(\mathrm{m})$

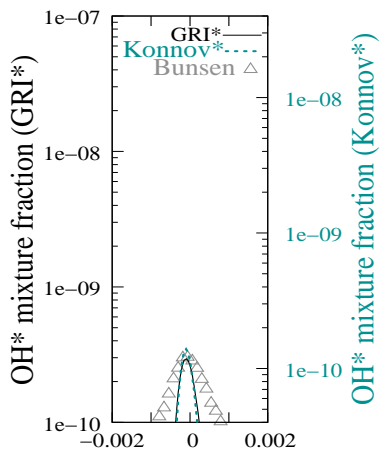

distance to the flame front $(\mathrm{m})$

Figure 10: Comparison of measured $\mathrm{OH}^{*}$ profiles with computed profiles using the GRI* reaction mechanism. The profiles are plotted at $\pm 2 \mathrm{~mm}$ of the flame front. The chemiluminescence signal intensity from experiments on Bunsen and V-flames are compared to predicted molar fractions for various equivalence ratios, temperatures, and steam contents. 
(11a) $T_{u}=400 K$

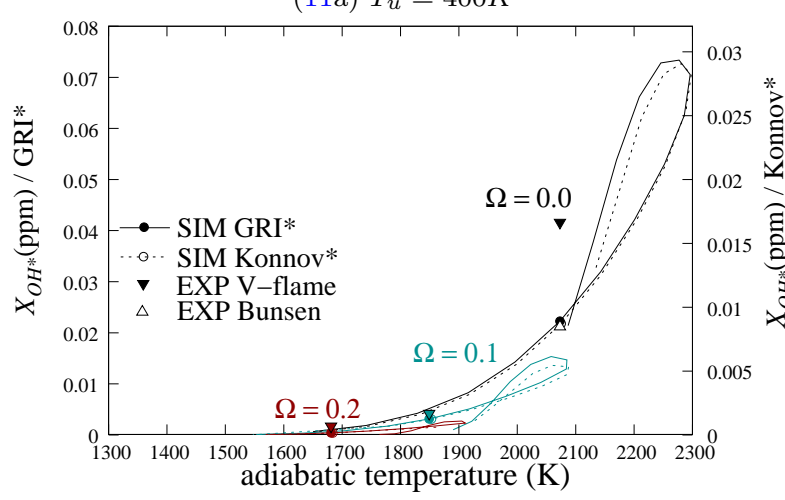

(11b) $T_{u}=480 K$

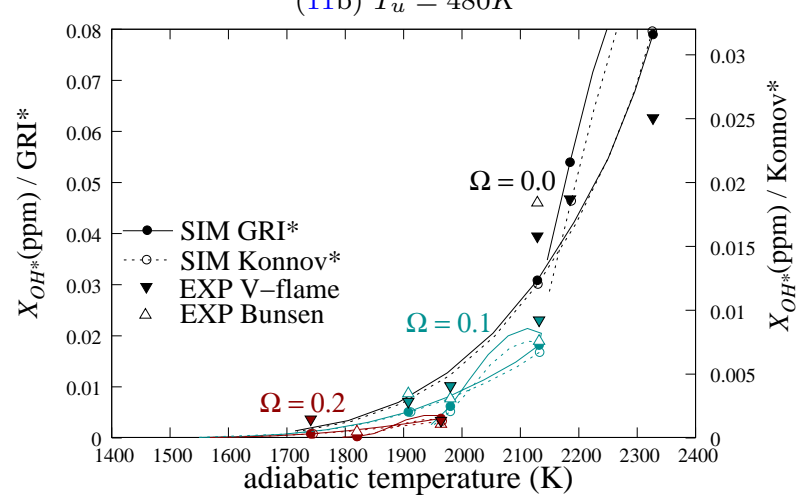

Figure 11: Plots of simulated and measured $\mathrm{OH}^{*}$ concentrations as a function of the computed adiabatic flame temperature. Points correspond to the 12 operating conditions of Fig. 10.

\section{Conclusions}

A new nozzle burner with an adjustable rectangular slot, designed to study laminar to slightly turbulent combustion of methane-air-steam mixtures, is presented. Bunsen flames and rod-stabilized V-flames are attached at ultra-wet conditions until the detachment of the flame. Turbulent burning velocities and $\mathrm{OH}^{*}$ profiles are extracted and compared to both laminar measurements available and numerical predictions using GRI-Mech and Konnov 0.5 mechanisms. The chemiluminescence of hydroxyl radicals is also compared to simulations for further validation.

The mechanisms are able to predict the strong decrease of the measured turbulent burning velocity with steam content up to $\Omega=25 \%$ of steam into the air. Excellent agreement of the influence of steam $\left(S_{L}^{\text {wet }} / S_{L}^{d r y}\right)$ with previous experiments and with the simulations is achieved. It is evidenced that a methane-air flame at ultra-wet conditions might be more than three times slower than a dry flame. Assuming the light intensity from the $\mathrm{OH}$ chemiluminescence is proportional to the mixture fraction of $\mathrm{OH}^{*}$, the modified mechanisms are also found able to qualitatively predict this chemiluminescence when varying the temperature, the equivalence ratio or the steam content. A wider range of operating conditions than found in the literature is presented. At wet and lean conditions, Bunsen flames of methane-air are found difficult to stabilize in comparison with V-flames. However, stabilization is possible and an increase of the inlet temperature seems interesting to increase this stability zone.

\section{Acknowledgement}

The authors thank Andy Göhrs for his help and Phoebe Kuhn, Katharina Göckeler, Alexander Troyke, Eduard Höschele, Finn Lückoff, Ricardo Mevert, Richard Steinert to make these experiments possible. The research leading to these results has received funding from the European Research Council under the ERC grant agreement $n$ 247322, GREENEST.

\section{References}

[1] Göke S, Göckeler K, Krüger O, Paschereit CO. Computational and experimental study of premixed combustion at ultra wet conditions. ASME Turbo Expo 2010, ASME Paper 2010-GT-23417 (2010).

[2] Göke S, Paschereit CO. Influence of steam dilution on NOx formation in premixed natural gas and hydrogen flames. $50^{\text {th }}$ AIAA Aerospace Science Meeting. AIAA-2012-1272 (2012).

[3] Rallis CJ, Garforth AM. The determination of laminar burning velocity. Progress in Energy and Combustion Science 6 (1980) 303-329.

[4] Mazas A, Lacoste D, Schuller T. Experimental and numerical investigation on the laminar flame speed of CH4/O2 mixtures diluted with CO2 and H2O. ASME Turbo Expo 2010, ASME Paper 2010-GT-22512 (2010). 
[5] Mazas AN, Fiorina B, Lacoste DA, Schuller T. Effects of water vapor addition on the laminar burning velocity of oxygenenriched methane flames. Combustion and Flame 158 (12) (2011) 2428-2440.

[6] Koroll GW, Mulpuru SR. The effect of dilution with steam on the burning velocity and structure of premixed hydrogen flames. Symposium (International) on Combustion 21 (1988) 1811-1819.

[7] Kobayashi H, Yata S, Ichikawa Y, Ogami Y. Dilution effects of superheated water vapor on turbulent premixed flames at high pressure and high temperature. Proceedings of the Combustion Institute 32 (2009) 2607-2614.

[8] Lecordier B, Trinite M. Etude de l'interaction de la propagation d'une flamme premelangee avec le champ aerodynamique, par association de la tomographie laser et de la velocimetrie par images de particules. PhD Thesis, Universit de Rouen (1997).

[9] Albin E, DAngelo Y. Assessment of the Evolution Equation Modelling approach for three-dimensional expanding wrinkled premixed flames. Combustion and Flame 159 (5) (2012) 1932-1948.

[10] Babkin VS, V'yun AV. Effect of water vapor on the normal burning velocity of a methane-air mixture at high pressures. Combustion, Explosion, and Shock Waves 7 (1971) 339-341.

[11] Koroll GW, Kumar RK, Bowles EM. Burning velocities of hydrogen-air mixtures. Combustion and Flame 94 (1993) $330-340$.

[12] Galmiche B, Halter F, Foucher F, Dagaut P. Effects of Dilution on Laminar Burning Velocity of Premixed Methane/Air Flames, Energy \& Fuels (2011).

[13] Varea E, Modica V, Vandel A, Renou B. Measurement of laminar burning velocity and Markstein length relative to fresh gases using a new postprocessing procedure: Application to laminar spherical flames for methane, ethanol and isooctane/air mixtures. Combustion and Flame 159 (2) (2011) 577-590.

[14] De Goey LPH, Somers LMT, Bosch WMML, Mallens RMM. Modeling of the small scale structure of flat burner-stabilized flames. Combustion science and technology 104 (1995) 387-400.

[15] Selle L, Poinsot T, Ferret B. Experimental and numerical study of the accuracy of flame-speed measurements for methane/air combustion in a slot burner. Combustion and Flame 158 (2011) 146-154.

[16] Dhué Y. Etude numérique et expérimentale de linfluence de lhumidité de l'air sur la combustion. Application aux stratégies de réduction démissions polluantes et de consommation des moteurs à pistons. PhD Thesis, Institut National Polytechnique de Toulouse (2009).

[17] Vreman AW, van Oijen JA, de Goey LPH, Bastiaans RJM. Direct numerical simulation of hydrogen addition in turbulent premixed Bunsen flames using flamelet-generated manifold reduction. International journal of hydrogen energy 34 (2009) $2778-2788$.

[18] Hall JM, Petersen EL. An optimized kinetics model for OH chemiluminescence at high temperatures and atmospheric pressures. International journal of chemical kinetics 38 (2006) 714-724.

[19] Su Y. Flow analysis and design of three-dimensional wind tunnel contractions. AIAA journal 29 (1991) 1912-1920.

[20] Chatterjee A. An introduction to the proper orthogonal decomposition. Current Science-Bangalore 78 (2000) 808-817.

[21] Cordier L, Bergmann M. Proper orthogonal decomposition: an overview. Lecture series, von Karman Institute for Fluid Dynamics (2002).

[22] De Boor C, Rice JR. Least Squares Cubic Spline Approximation, II-Variable Knots. Technical report. Department of computer science, Purdue University (1968).

[23] Wang BL, Olivier H, Grönig H. Ignition of shock-heated H2-air-steam mixtures. Combustion and flame 133 (2003) 93-106.

[24] Gurentsov EV, Divakov OG, Eremin AV. Ignition of multicomponent hydrocarbon/air mixtures behind shock waves. High temperature 40 (2002) 379-386.

[25] Konnov AA. Implementation of the NCN pathway of prompt-NO formation in the detailed reaction mechanism. Combustion and Flame 156 (2009) 2093-2105.

[26] Shy SS, Lin WJ, Wei JC. An experimental correlation of turbulent burning velocities for premixed turbulent methane-air combustion. Proceedings of the Royal Society of London. Series A: Mathematical, Physical and Engineering Sciences 456 (2000).

[27] Poinsot T, Veynante D. Theoretical and numerical combustion. RT Edwards, Inc. (2005).

[28] Miyauchi T, Mori Y, Yamaguchi T. Effect of steam addition on NO formation. Symposium (International) on Combustion 18 (1) (1981) 43-51.

[29] Seiser R, Seshadri K. The influence of water on extinction and ignition of hydrogen and methane flames. Proceedings of the Combustion Institute 30 (1) (2005) 407-414.

[30] Le Cong T, Dagaut P. Experimental and detailed modeling study of the effect of water vapor on the kinetics of combustion of hydrogen and natural gas, impact on NO x. Energy \& Fuels 23 (2) (2009) 725-734.

[31] Goodwin DG. An open source, extensible software suite for CVD process simulation. California Institute of Technology, Division of Engineering and Applied Science (2003).

[32] Konnov AA. Development and validation of a detailed reaction mechanism for the combustion of small hydrocarbons. $28^{\text {th }}$ Symposium (Int.) on Combustion Edinburgh, Abstr. Symp. Pap, 2000, p. 317.

[33] Smith GP, Golden DM, Frenklach M, Moriarty NW, Eiteneer B, Goldenberg M, Bowman CT, Hanson RK, Song S, Gardiner WC, Lissianski VV, Qin Z. GRI-Mech 3.0. http://www.me.berkeley.edu/gri_mech/ (2000). 